\title{
GSR and breathing amplitude related to emotional reactions to music
}

\author{
HAROLD A. RIES, Sacramento State College, Sacramento, \\ Calif. 95819
}

A variety of musical selections was presented to 19 Ss while GSR and respiratory reactions were simultaneously recorded. Ss rated the stimuli in terms of their affective and effective reactions to the music immediately after the presentation of each selection. The results indicated that the GSR was not related to affective reactions to music and was related to effective reactivity only when measures of extroversionintroversion were included. Breathing amplitude was found to be significantly correlated with affective and effective reactivity to the music. It was concluded that this latter measure seemed more promising in this type of research.

A considerable amount of research has been directed towards the relationships between physiological reactions and affective or evaluative responses to music. The most frequently used measure for these physiological reactions has been the GSR, but results are often confusing or contradictory. Phares (1934) concluded that the GSR was not particularly useful in this type of research, while Henkin (1957) found clear-cut relationships between the GSR and the rhythmic and familiarity variables. There was no significant correlation, however, between the GSR and musical style, composition, or orchestration. Traxel \& Wride (1959) used three types of music and reported that GSR reactions were strongest to jazz selections but no significant correlations between preferences and the GSR were found, and they accounted for this discrepancy on the basis of conventional group values. The present investigation was an attempt to study the relationships between emotional responses and physiological reactions to musical selections using two measures of the physiological reactions, the GSR and breathing amplitude, and to use a wider variety of stimuli than typically have been used. To determine if general personality variables or response tendencies may partially account for the confusion in this area, measures of extroversion-introversion also were included. SUBJECTS

Subjects included nine male and 10 female undergraduate students enrolled in a course in clinical psychology at Sacramento State College. Their ages ranged from 21 to 41 years with a mean age of 23.5 years. All Ss volunteered for the study and were naive regarding its methods and purposes. Differences in age and sex between the extrovert-introvert groups were negligible.

\section{APPARATUS}

The apparatus consisted of a three-channel, single-speed Associated Research Incorporated polygraph, Model 6308, on which the GSR and respiration reactions were recorded. The musical selections were presented in a sound-deadened room with a Sony. Model TC-530, stereophonic tape recorder through Sharpe. Model MA-9, stereophonic headphones. The musical selections. listed in their randomly predetermined order of presentation, included: (1) Prokofiev's "Le Prince et la Princesse," performed by the London Symphony Orchestra; (2) "Loch Rannock" and "The Seige of Delhi," performed by the Royal Highland Regiment; (3) "Ira Hayes," by Johnny Cash; (4) Bartok's "String Quartet No. 2 opus 17," performed by the Fine Arts Quartet; (5) "Crystal Ship," by The Doors: (6) "Societies' Child," by Janice Ian; and (7) "Within You Without You," by the Beatles.

\section{PROCEDURE}

Subjects were tested individually with the Maudsley Personality Test (1962) immediately prior to the experimental situation. Introverts were defined by a score of 0 to 24 , ambiverts by a score of 25 to 33, and extroverts by a score of 34 to 48. After the apparatus were connected and the physiological reactions were stabilized, each $\mathbf{S}$ was instructed to listen to the music and rate it on a form provided in terms of the music's affective reaction on him, a five-point scale ranging from Very Much Like to Very Much Dislike, and effective reaction on him, a five-point scale ranging from Very Much Effect to No Effect, during a 1-min interval between each musical selection. Physiological data for each $\mathbf{S}$ were assessed for the modal amplitude of response for each musical selection by three raters, and their combined ratings were correlated with the Ss' judgments and test scores.

\section{RESULTS}

The relationships between the physiological reactions and the affective and effective responses to the musical stimuli were determined by means of Pearson. Product-Moment correlation coefficients. The relationship between the modal GSR reaction and affective responses was nonsignificant $(r=.02, d f=132$, n.s.) as was the correlation between the modal GSR reaction and effective responses $(r=.04, d f=132$, n.s.). As reported by Traxel \& Wride (1959), the GSR reactions were obviously present but the correlations between these reactions and the judgmental responses seemed absent. When, however, the Ss were categorized according to their extroversion-introversion scores, a trend became apparent. While this trichotomy seems irrelevant to the affective judgments, there was a significant positive correlation between the modal GSR amplitude and the stated effective responses in the extroverted $S s(r=.30, d f=69, p<.05)$ and a negative correlation between these variables in introverted $S s(r=-.28$, $\mathrm{df}=41, \mathrm{p}<.10>.05)$. These trends were not observed in ambiverted $S s(r=.06, d f=20$, n.s.). These data would seem to indicate that while the GSR is not significantly correlated with how much a $\mathrm{S}$ likes or dislikes a musical selection, there is a significant, although somewhat complex, relationship between the GSR and how much a $S$ reports he is affected by that music.

The relationship between the modal breathing amplitude and affective responses to the musical stimuli was found to be highly significant $(\mathrm{r}=.48, \mathrm{df}=132, \mathrm{p}<.01)$ and indicates that the more a $S$ reports liking a musical selection, the deeper his breathing tends to become. This trend was apparent in 17 of the 19 Ss. The relationship between the modal breathing amplitude and effective responses was also significant $(r=.31$, df $=132, p<.01$ ) and indicates that the more a $S$ reports he is being affected by the music, the deeper his breathing becomes. It may be noted that this correlation is of essentially the same magnitude as was found with the GSR; but it seems to indicate a more universal tendency, that is, categorizing the Ss in terms of their extroversion-introversion scores did not appreciably affect the correlations.

Previous studies attempting to assess the relationship between physiological reactions and phenomenological responses to musical stimuli have tended to arrive at contradictory results. The present study would seem to support this confusion insofar as the use of the GSR is concerned. While the GSR reactions were obvious, there was 
Table 1

Means

Reinforcement Conditions

\begin{tabular}{|c|c|c|c|c|c|}
\hline & & Positive & No & Negative & Combined \\
\hline \multirow{3}{*}{ Sex } & Male $(N=10)$ & 1.20 & 1.50 & 1.80 & 1.50 \\
\hline & Female $(N=11)$ & 2.00 & 1.30 & 2.60 & 1.96 \\
\hline & Total Sample & 1.60 & 1.40 & 2.20 & \\
\hline
\end{tabular}

\section{REINFORCEMENT TREATMENTS}

For each of the positive and negative reinforcement conditions, $E$ used three sentences. He repeated the first one after 30 and $60 \mathrm{sec}$; the other two were used, in the order listed, after 90 and $120 \mathrm{sec}$. For the Positive-Reinforcement Condition, these were (a) "I like that," (b) "That's very good," and (c) "That's a good point." For the NegativeReinforcement Condition, the negative counterparts of the preceding statements were used. During the No-Reinforcement Condition, E listened silently to S's story.

\section{RESULTS}

The mean number of theme changes for each condition for both sexes appears in Table 1. The reinforcement conditions were found to differ in the number of themes elicited $[F(2,36)=7.79, p<.05]$. A follow-up comparison of the three pairs of means was performed using the Newman-Keuls procedure (Winer, 1962, pp. $309 \mathrm{ff}$.). It was found that the number of themes produced under the NegativeReinforcement condition was statistically greater than that under either the No-Reinforcement or Positive-Reinforcement conditions. The No-Reinforcement and PositiveReinforcement conditions did not differ from each other.

The main effect of Reinforcement conditions interacted with $\operatorname{Sex}[F(2,36)=8.23, p<.05]$. Follow-up comparisons of cell means revealed that while the difference between positive and negative reinforcement was in the same direction for both boys and girls, it was relatively greater for boys.

\section{CONCLUSION}

It seems apparent that negative social reinforcement changed the verbal behavior of the $S s$ in the present experiment. In a situation analagous to taking a standardized projective test, Ss showed a relatively greater number of themes following negative reinforcement, indicating that negative reinforcement was associated with a change in response. Since the Positive- and No-Reinforcement conditions did not differ from each other, it is not possible to conclude that positive reinforcement increases the duration of a particular response in such a situation. Such an inference awaits the inclusion of measures such as quantity of verbal material and, perhaps, nonverbal behavior during the session. The interaction between sex and reinforcement had relatively more effect on boys than on girls. This is consistent with an interpretation that boys are more sensitive to the approval of adult males than are girls.

Studies cited above have found positive social reinforcement associated with increases in the responses reinforced, and its removal associated with decrease of such responses. The present study supports only the idea that negative reinforcement reduces the probability of continuing the ongoing response. The differences in findings are probably due to the very different nature of the responses involved. The observations made here were not of díscrete response units as were those of the previous studies. They were related to response duration. Further work might be directed towards a direct comparison of response measures.

\section{REFERENCES}

GEWIRTZ, J., \& BAER, D. The effect of brief social deprivation on behaviors for a social reinforcer. Journal of Abnormal \& Social Psychology, 1958, 56, 49-56.

HARRIS, F., WOLF, M., \& BAER, D. Effects of adult social reinforcement on child behavior. Young Children, 1964, 20, 8-17.

HOROWITZ, F. Social reinforcement effects on child behavior. In $W$. Hartup and N. Smothergill (Eds.), The Young Child. Washington, D. C.: National Association for the Education of Young Children, 1967. Pp. 27-41.

OFFENBACH, S., \& MEYER, W. Adult silence as a reinforcer. Journal of Experimental Child Psychology, 1964, 1, 294-300.

STEVENSON, H., \& HILL, K. The effects of social reinforcement and nonreinforcement following success and failure. Journal of Personality, 1965, 33, 418-427.

WINER, B. J. Statistical principles in experimental design. New York: McGraw-Hill, 1962.

\section{NOTE}

1. Now at the University of Washington. The authors wish to thank the staff of the Fresno State College Laboratory School. This study was conducted by the senior author under the direction of the junior author as part of the requirements for an A.B. in Psychology at Fresno State College.

\section{(Continued from page 65)}

essentially no correlation between these reactions and the Ss' judgments of how much they liked or disliked the stimuli. There were relationships between these reactions and how much the Ss reported that they were affected by the music, but positive correlations were limited almost exclusively to extroverted Ss. The relationships between these variables in introverted Ss assumed the form of negative correlations, and seems to imply that introverts may be misinterpreting bodily sensations. While the GSR reactions seem to be markedly influenced by personality styles, breathing reactions to the music were less subject to extrastimulus variables. Indeed, these latter reactions were correlated with the Ss' perceived effectiveness of the stimuli at approximately the same magnitude as the GSR but were not subject to the influences of extroversion-introversion tendencies. The relationship between the modal breathing amplitude and the Ss' affective responses were highly correlated and indicates that the more a $S$ reports liking a selection, the deeper his breathing becomes. This supports earlier studies (Plutchic, 1959; and Poole et al, 1966) indicating that a strong relationship exists between respiration reactions and emotional responses to auditory stimuli.

\section{REFERENCES}

EYSENCK, H. J. The Maudsley Personality Inventory. San Diego: Educational and Industrial Testing Service, 1962.

HENKIN, R. 1. The prediction of behavior response patterns to music. Journal of Psychology, 1957, 44, 111-127.

PHARES, M. L. Analysis of musical appreciation by means of psychogalvanic technique. Journal of Experimental Psychology, 1934, 17, 119-140.

PLUTCHIC, R. The effects of high intensity intermittent sound on performance, feeling, and physiology. Psychological Bulletin, 1959, $56,113-151$.

POOLE, R., GOETZINGER, C. P., \& ROUSEY, C. L. A study of the effects of auditory stimulation on respiration. Acta-Otolaryngologica, $1966,61,143-152$.

TRAXEL, W., \& WRIDE, G. Changes in GSR while listening to music. Zeitschrift für experimentelle und angewandte Psychologie, 1959,6, 293-309. 